\title{
Transforming Energy Technologies for Climate Neutrality Goals
}

\author{
Ashutosh Tiwari* (D)
}

The world is facing major problems related to global warming, climate change, anthropogenic greenhouse gas emissions, and environmental degradation. They implicate a major worry to take immediate measures to rectify the ways and methods to build a clean world for the future generation to live blissfully. The technological revolution paves a way to combat the current terrible situation using numerous sustainable measures by the advancement of materials. The clean energy transition is mostly adopting in the transport and mobility sectors for reducing the emissions of vehicles. The present scenario of the global climate sets urgent needs to demonstrate country wise a long-term policy for clean, renewable, and net-zero waste power generation in line with climate neutrality goals.

\section{European Green Deal and Paris Agreement}

The range of climate policies have been taken up to ensure the reduction of the anthropogenic greenhouse gas emission which itself will help in climate neutrality being aimed by the organizations and countries. Climate change are an existential threat to counterbalance these challenges, the European Green Deal will transform the European Union into a strong economy by various strategies $[\mathbf{1}, \mathbf{2}]$. The European Green Deal is set on the goal of changing the procedure of energy production and consumed to bring in sustainability for example to target cutting down greenhouse gas emission by 50\% till 2030 and an inclusive climate neutrality by 2050 [3]. This ambitious project will create a very positive impact on the climate control in the European and neighboring regions. The European Commission also aims to reduce the dependence on fossil fuels by half of this decade.

The European Green Deal intends to reduce the dependency on oil and natural gas for energy requirement. Likewise, European Union (EU) has taken up the decarbonization of the EU energy system, which will benefit in attaining the goal of climate neutrality. The Paris Agreement is a historic agreement bringing all nations into a common cause and legally binding with international treaty on climate change [4]. Overall, it is helpful in a clean energy transition, means control greenhouse gas emissions and attaining carbon neutrality within targeted timeline [4].

Institute of Advanced Materials, IAAM, Gammalkilsvägen 18, Ulrika 590 53, Sweden

*Corresponding author:

E-mail: director@iaam.se, Tel.: (+46) 1313-2424

DOI: 10.5185/amlett.2021.091658
The European Green Deal has also opened innovations, new investments, and job opportunities and at the same time plans at addressing issues like poverty, unemployment, tackling inequality and improvement of health and wellbeing in the society. Some of the main objectives aimed by the European Green Deal towards clean energy transition are integrated by building renewable energy resources. The European Green Deal have some major challenges to face such as reduction of fossil fuel demand, which is going to affect neighboring regions and oil and natural gas engulfs having a major part of exportation in the neighborhood's budgets. But this will be substantially compensated by diversifying its export product and market. For example, In October 2020, Russia has adopted hydrogen development scheme to substitute fossil fuel. Such national policy will also accelerate cleantech market for green investment.

\section{Clean energy realisations and climate neutrality}

Clean energy transition is one of the most important activity to be done which will help reduce greenhouse gas emission and give a healthy living planet to live (Fig. 1). The sustainable energy fulfils our requirement without compromising the requirements of future [5]. The European Commission promotes the growth of the market for zeroand low- emissions vehicles.

Moreover, adoption of common agreement on climate change through dominant countries representing 70 per cent of the world economy and more than 65 per cent of damaging greenhouse gasses have committed to accomplish net zero emissions by 2050 . The global mission of carbon neutrality by middle of the century is taking shape with efforts of European goals and Paris Agreement [4]. The EU plan of climate neutral lies under the Paris Agreement and European Green Deal for fixed 


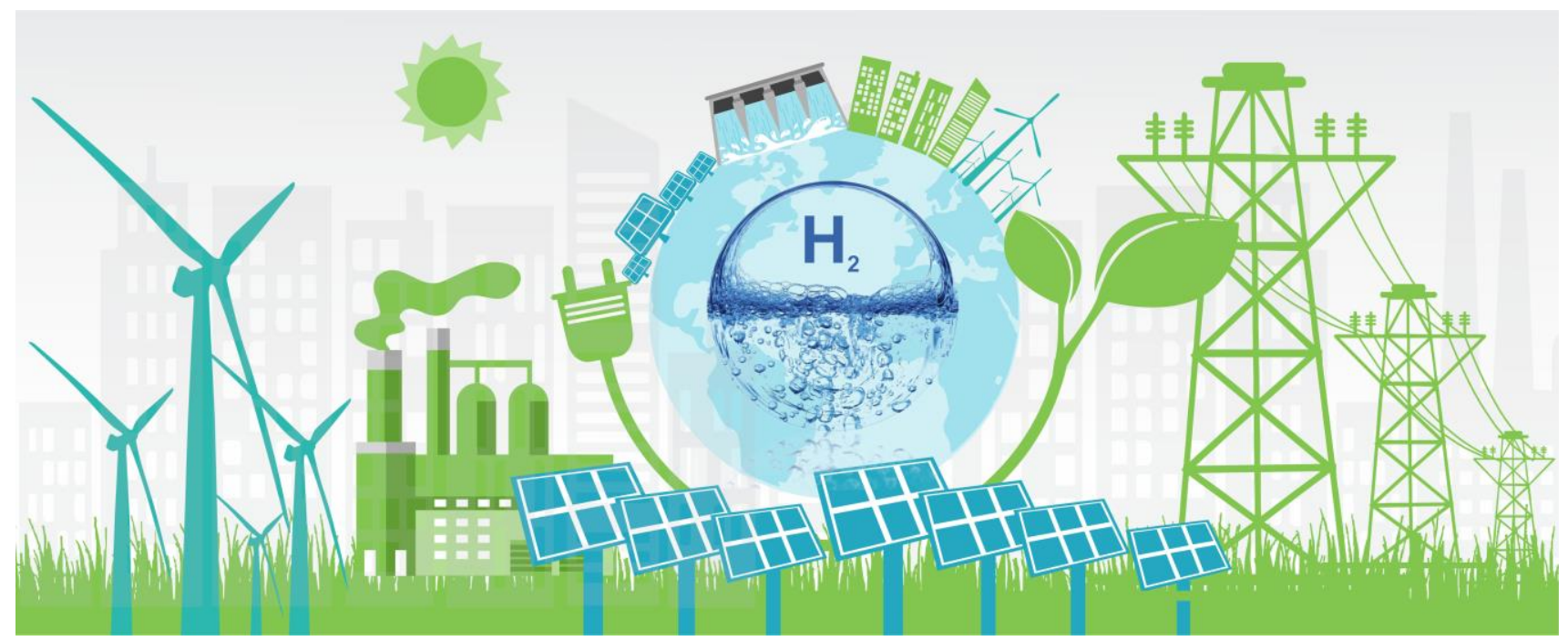

Fig. 1. Translation of clean energy technology to achieve climate neutrality goals.

commitment of better environment [2-6]. Fig. 2 is listed the top 20 countries working in the clean energy R\&D based on Scopus data taken on $4^{\text {th }}$ September 2021. The major countries involved were China, USA, India, UK, Germany, Japan, Canada, Italy, Australia, South Korea, France, Spain, Iran, Malaysia, Turkey, Brazil, Saudi Arabia, Russian Federation, Netherlands, Saudi Arab and Taiwan.

The cleaning of the energy system is also aimed at by the European Green Deal for which it proposes to reconnect with exclusive integrated renewable energy technology. At the same time, it promotes for smart house schemes, buildings based on energy efficient utilization.

\section{Sustainable, secure, and cheaper energy system}

Understanding impact of renewable energy (hydro, solar and wind power) for cost effective energy generation and adoptive policies for non-European countries allowing the world to shift properly towards sustainability goals. Study shows that extensive use of renewable energy effects in reduction of $\mathrm{CO}_{2}$ emissions, while regional diversity exists across continent for energy research [7]. It indicates that both financial development and the renewable energy sectors in the Middle East and North Africa are still weak such as with respect to improvements in the environmental quality and economic growth [8]. On the other hand, sustainable economic growth in the ASEAN region is accomplished by moderating population growth with higher use of renewable energy [9]. It creates idea model having energy security with human growth as well as strong sustainable measures.

Hydrogen as a versatile energy carrier for various sectors and works as sustainable and secure paradigm [10]. We know, sustainable environment depends on a secure and cheaper climate neutral energy system. By adapting advance materials technologies in water, wind, solar, geothermal, bioenergy, hydrogen etc., we can move forward towards sustainable energy productions. European Union has proposed an efficient hydrogen strategy for the climate neutral Europe. This tactical roadmap offers a tangible policy outline in which the European Clean Hydrogen Alliance, European Battery Alliance (a teamwork among public authorities,

Fig. 2. Top 20 Countries in clean energy research items in Scopus at dated $4^{\text {th }}$ September 2021. 


\section{Advanced Materials Letters https://aml.iaamonline.org}

business, and municipal society) will develop a venture program and a pipeline of tangible plans [11]. Similarly, other countries like United States of America launched Department of Energy Hydrogen Program Plan [12]; China launched China Hydrogen Alliance, a governmentsupported industry group [13]; India launched National Hydrogen Mission [14], Japan builds a "hydrogen society" at the Summer Olympics [15] and other countries are also planning to utilize the hydrogen towards a climate neutral world. Energy innovations have created jobs, boosted economic and impact positively on green societal growth [16]. Gaining sustainability in energy sector needs more emphasize in transportation, manufacturing, buildings, and power grids fields, where innovation, digital integration and data analytics with government energy programs makes it reality before the time.

\section{Energy efficient technologies and statistics}

High Performance Computing, machine learning, sensor integration and data analytics technology with cloud system helpful in provide solutions for data processing and monitoring in clean energy. Advanced data management system in the energy sector including renewable and nonrenewable contributes to performance, maintenance, distribution cost-effectively $[\mathbf{1 7 , 1 8}]$.

Science and technology in clean energy sector can be understand with Fig. 3 in subject wise clean energy data. Engineering, environmental science, physics, chemical engineering, earth science, business, and management, etc. were on priority subjects in clean energy research. Fig. 4 demonstrates various top resource journals publishing for literature and knowledge sharing.

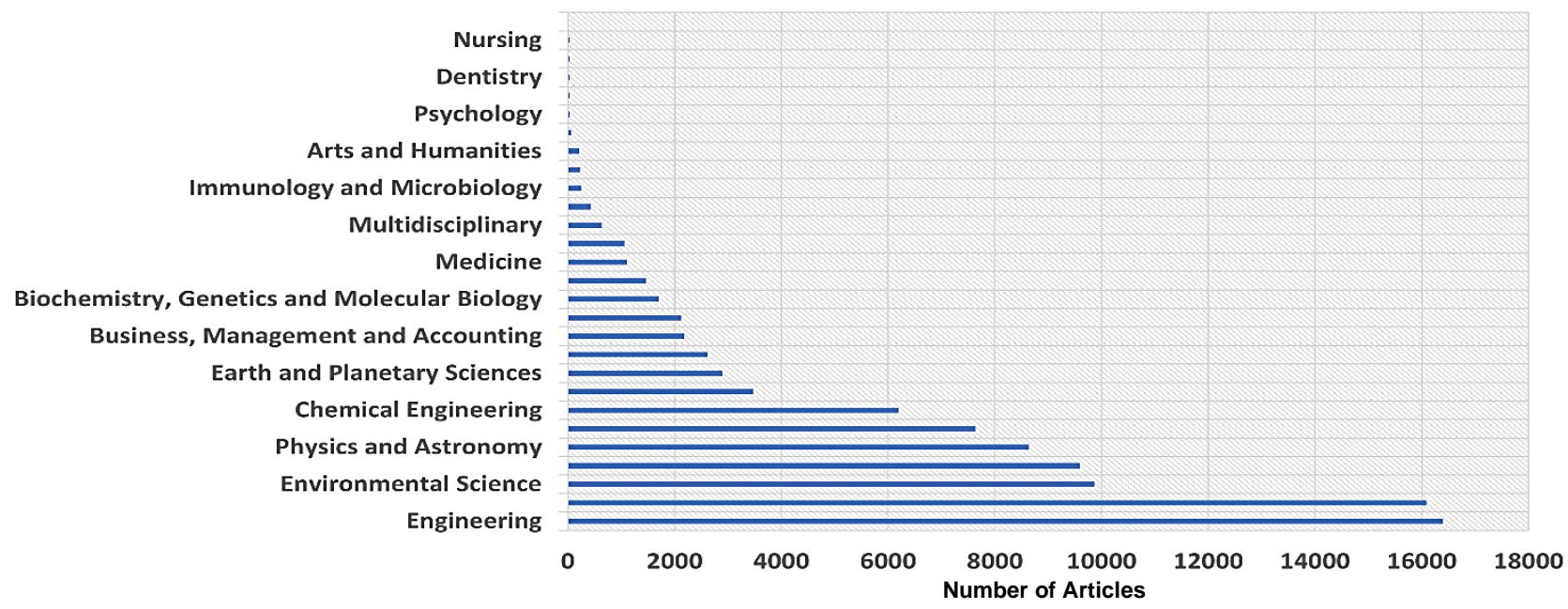

Fig. 3. Subject wise clean energy research items in Scopus at dated $4^{\text {th }}$ September 2021.

Iop Conference Series Materials Science And Engineering Energy Conversion And Management Sustainability Switzerland

Proceedings Of SPIE The International Society For Optical Engineering Journal Of Physical Chemistry C Aip Conference Proceedings Journal Of Materials Chemistry A Applied Surface Science Energy Procedia Renewable Energy Applied Energy Energies Energy Iop Conference Series Earth And Environmental Science Energy Policy Surface Science Physical Review B Condensed Matter And Materials Physics Renewable And Sustainable Energy Reviews Journal Of Cleaner Production International Journal Of Hydrogen Energy

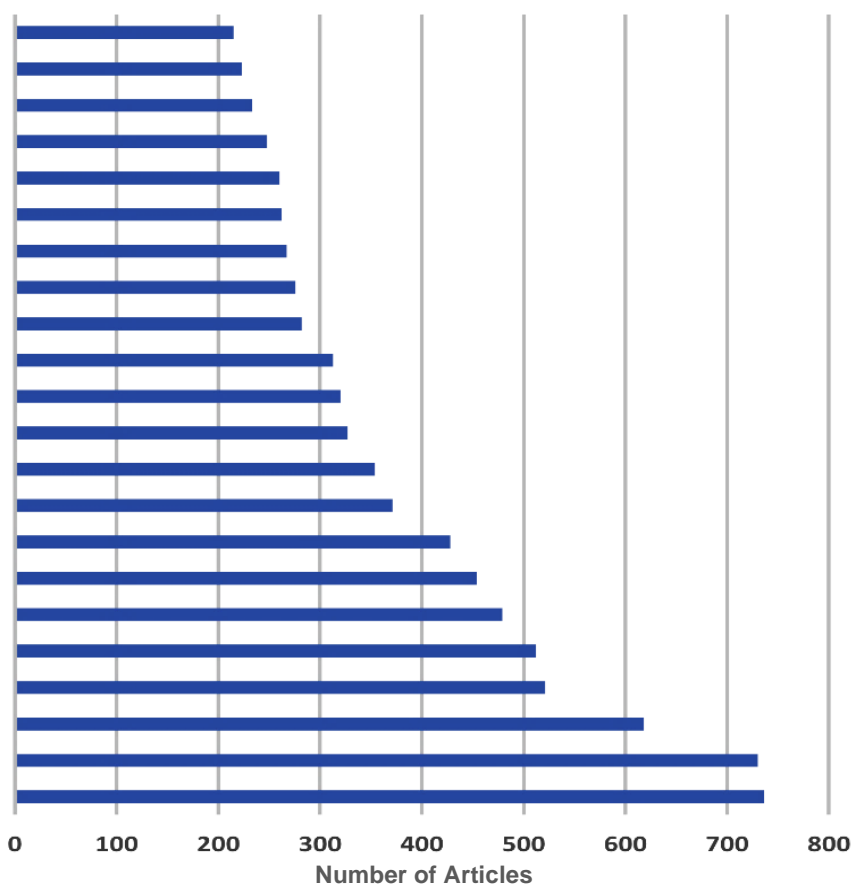

Fig. 4. Top resource journals having more than 200 Articles in clean energy research items in Scopus at dated $4^{\text {th }}$ September 2021. 


\section{Advanced Materials Letters https://aml.iaamonline.org}

The energy production research with efficiency technologies integration and innovative move helps to take decision of investment and policies [19]. Renewable energy drivers impact through financial, policy and regulations. With the use of technology solutions customers can reduce costs, risks and contribute to carbon reduction goals [20]. The green technologies have role in job creation in renewable energy sectors, understandable by IRENA statistics on renewable energy capacity and power generation [21].

\section{Organizational motives of attaining a climate neutral world}

The various organizations from different countries and regions have independently set their goals to take forward the motive of making the environmental neutral practices. The International Energy Agency works for energy security climate change and air pollution, energy access and efficiency, and much more. Accurate and timely energy statistics required for making policies, planning etc. [22]. UNSD data analytics proposes energy statistics in four workstreams for better understanding of energy requirement and making strategies [23]. Understanding the European Union statistics on the renewable energy for four major i) electricity, ii) heating and iii) cooling, and iv) transport consumption sectors are meeting for making long term regional strategies and policies [24].

The United Nations, the European Commission, International Association of Advanced Materials (IAAM) and many other organizations are working towards the motive of attaining a climate neutral world with curtailing of greenhouse gas emission. IAAM has moved into the next decade by proclaiming 'Advancement of Materials to
Sustainable and Green World' $[\mathbf{2 5}, \mathbf{2 6}]$. This association is committed for Materials Research and Innovations to facilitate sustainable developmental needs by 2030 .

The European Green Deal, the United Nations and the IAAM are working on the same line and for this they have adopted different set of proposals though syncing on achieving the healthier, sustainable, and clean planet. Under the EU countries intend to focus on five areas: (i) energy efficiency, (ii) renewables, (iii) greenhouse gas emissions reductions, (iv) interconnections, and (v) research and innovation. The EU seeks goals by 2030 in a fair, cost effective and competitive way.

The people realize that sustainable future is priorities with prioritised strategies of the zero waste, environment friendly and clean energy. The IAAM addressing the challenges of sustainability of materials research and innovation for climate neutral health, energy environment world R\&D network [27]. Fig. 5 showing the world top 25 organizations contributing to clean energy research and technology through their active performance.

One of the most important steps taken by the European Green Deal is to work with the nature for fighting against climate change by restoring forests, soils, wetlands, and peat lands. It becomes more resilient to climate change by improving health and wealth along with environmental balance. International transportation such as maritime and aviation should be more focused as well. In the latest development, the European Commission has adopted the first partnership agreement for 2021-2027 programming period to Greece, the first EU country to submit its strategic reference document for deploying more than 21 billion Euro of investments for its economic, social and territorial cohesion

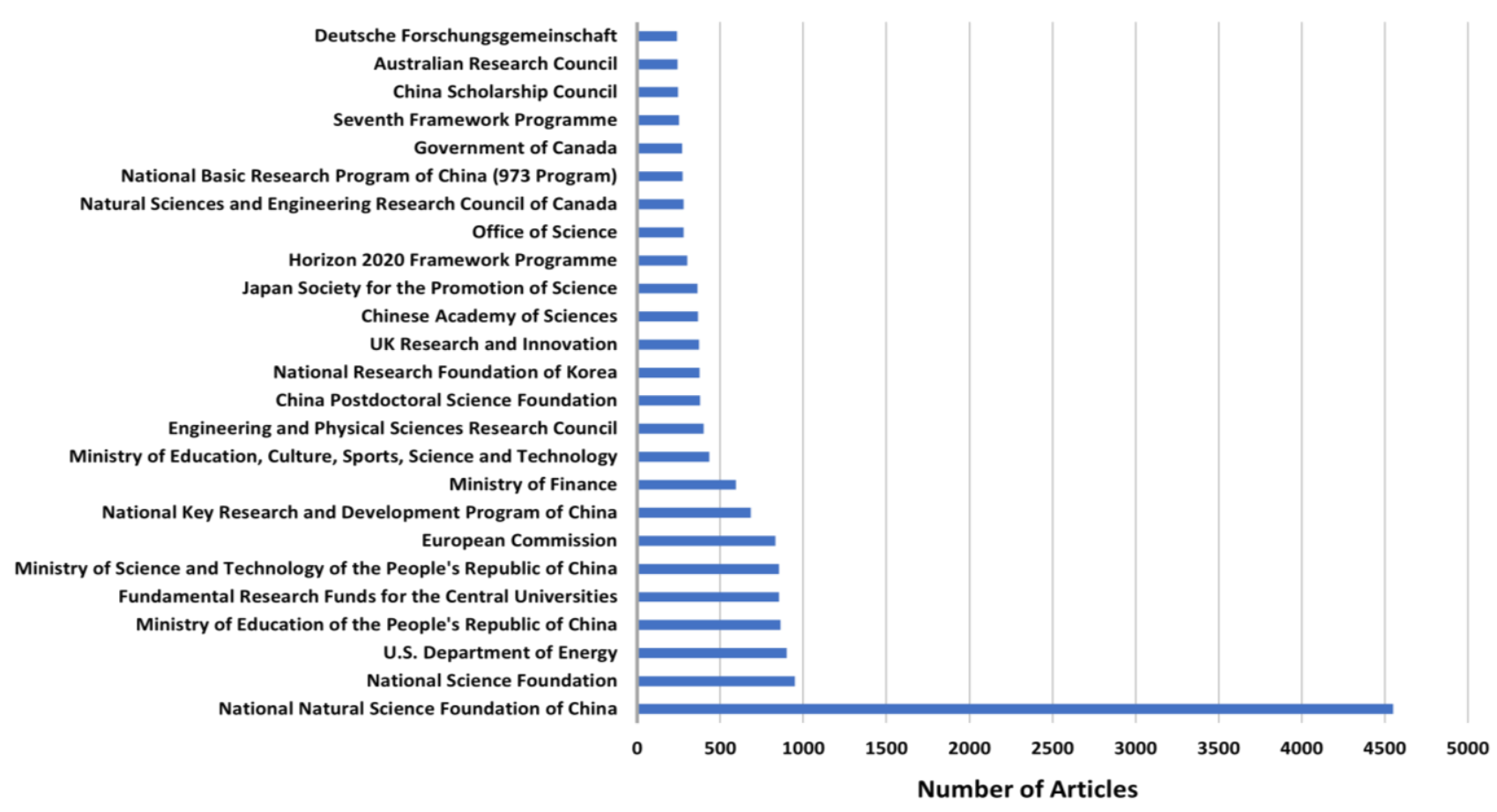

Fig. 5. Top 25 organizations contributing in Clean energy research and innovation items in Scopus at dated $4^{\text {th }}$ September 2021. 
Advanced
Materials Letters
https://aml.iaamonline.org

\section{Conclusion}

The intending journey of the transforming energy technology for climate neutrality is a long term but it has achieved its initial milestones and looks forward to creating a better, healthy, and sustainable world. Realizing the United Nations' Sustainable Development Goals (SDGs) required excellence in materials via green synthesis, zero waste design, intelligent characteristics, and innovative applications. The objectives of climate neutrality inspire researchers to drive their efforts for contributing to the building a green and zero waste planet using sustainable energy technology. Overall, considering all facts, IAAM has committed to work with United Nations' SDGs and European Green Deal for the climate neutral new decade.

\section{References}

1. Ashutosh Tiwari; "Advancing Materials towards Climate Neutrality by 2050". Advanced Materials Letters, 2021, 12, 8, 1-3. DOI: $10.5185 /$ amlett.2021.081650

2. "Climate change and counter strategies", viewed 3 September 2021, $<$ https://ec.europa.eu/info/strategy/priorities-2019-2024/europeangreen-deal_en>.

3. “A clean energy transition", viewed 3 September 2021, $<$ https://ec. europa.eu/info/strategy/priorities-2019-2024/europeangreen-deal/ energy-and-green-deal_en>.

4. "Paris Agreement as Legally binding international treaty on climate change", viewed 3 September 2021,

$<$ https://unfccc.int/process-and-meetings/the-paris-agreement/theparis-agreement>.

5. "The sustainable energy information", viewed 3 September 2021, <https://en.wikipedia.org/wiki/Sustainable_energy>.

6. "The carbon neutrality by 2050", viewed 3 September 2021, $<$ https://www.un.org/sg/en/content/sg/articles/2020-12-11/carbonneutrality-2050-the-world\%E2\%80\%99s-most-urgent-mission>.

7. Dong K., Hochman G., Zhang Y. et. al. CO2 emissions, economic and population growth, and renewable energy: empirical evidence across regions. Energy Economics, 2018, 75, 180-192. https://doi.org/10.1016/j.eneco.2018.08.017

8. Lanouar Charfeddine, Montassar Kahia. Impact of renewable energy consumption and financial development on $\mathrm{CO} 2$ emissions and economic growth in the MENA region: A panel vector autoregressive (PVAR) analysis. Renewable Energy, 2019, 139, 198-213. https://doi.org/10.1016/j.renene.2019.01.010

9. Vo, D.H.; Vo, A.T.; Renewable energy and population growth for sustainable development in the Southeast Asian countries. Energ. Sustain Soc., 2021, 11, 30. https://doi.org/10.1186/s13705-021-00304-6

10. "Future technology of energy", viewed 3 September 2021, <https://www.siemens-energy.com/global/en/priorities/futuretechnologies/hydrogen.html .

11. "Communication from the Commission to the European Parliament, the Council, The European Economic and Social Committee and The Committee of the Regions-A hydrogen strategy for a climate-neutral Europe" viewed 3 September 2021, <https://ec.europa.eu/energy/sites/ener/files/hydrogen_strategy.pdf $>$.

12. "Department of Energy Hydrogen Program Plan", viewed 03 September 2021,

<https://www.hydrogen.energy.gov/pdfs/hydrogen-program-plan2020.pdf>

13. "China's hydrogen roadmap: 4 things to know", viewed 03 September 2021,

$<$ https://asia.nikkei.com/Spotlight/Caixin/China-s-hydrogenroadmap-4-things-to-know>.
14. "Independence Day: PM Modi announces National Hydrogen Mission", viewed 03 September 2021,

$<$ https://www.livemint.com/news/india/independence-day-pmmodi-announces-national-hydrogen-mission11629002077955.html>.

15. "Japan bets on hydrogen to lift its ambitious carbon-neutral plans", viewed 03 September 2021,

<https://www.washingtonpost.com/climate-solutions/japanhydrogen-energy-carbon/2021/04/13/0dd68e4e-9229-11eb-aadcaf78701a30ca_story.html>.

16. "Sustainable, secure and cheaper energy system", viewed 03 September 2021,

<https://www.nrel.gov/docs/gen/fy19/72156.pdf>.

17. "Clean Energy Data science", viewed 03 September 2021, <https://www.discoverdatascience.org/industries/clean-energy/>.

18. “Technology of Energy”, viewed 03 September 2021, <https://www.tgs.com/our-insights/tgsai>

19. "Energy statistics research", viewed 03 September 2021, <https://www.nrel.gov/analysis/research.html>.

20. "Sustainable Energy", viewed 03 September 2021 , <https://www.tgs.com/sustainability>.

21. "Efficient statistical technology of Energy", viewed 03 September 2021, <https://www.irena.org/statistics>.

22. "Technology and statistics for Energy", viewed 03 September 2021, <https://www.iea.org/fuels-and-technologies>

23. "United Nations Energy Monitoring", viewed 03 September 2021, <https://unstats.un.org/unsd/energystats/>.

24. "EU Energy statistics", viewed 03 September 2021, $<$ https://ec.europa.eu/eurostat/statisticsexplained/index.php?title=Renewable_energy_statistics $>$.

25. "The Advancement of Materials to Sustainable and Green World", viewed 3 September 2021, $<$ https://www.iaamonline.org/advancement-of-materials-tosustainable-and-green-world>.

26. Ashutosh Tiwari; "Advanced Materials Research and Innovation Priorities for Accomplishing the Sustainable Development Goals". Advanced Materials Letters, 2021, 12, 6, 1-6. DOI: 10.5185/amlett.2021.061633.

27. "R\&D World Links and Decentralized Facilities", viewed 3 September 2021, < https://www.iaam.se/R\&D-world>. 